\title{
Living Kidney Donors Who Develop Kidney Failure: Excerpts of Their Thoughts
}

\author{
Colin M.E. Halverson ${ }^{f}$ Jackie Y. Wang ${ }^{d}$ Michael Poulson ${ }^{a}$ Jennifer Karlin ${ }^{b}$ \\ Megan Crowley-Matoka ${ }^{c}$ Lainie F. Ross ${ }^{\mathrm{e}, \mathrm{g}, \mathrm{h}}$ \\ ${ }^{a}$ Georgetown University School of Medicine, Washington D.C., ${ }^{b}$ Department of Family and Community Medicine, \\ University of California in San Francisco, San Francisco, Calif., ' Department of Medical Education-Medical Humanities \\ and Bioethics, Northwestern University Feinberg School of Medicine, dUniversity of Chicago Pritzker School of \\ Medicine, and ${ }^{\mathrm{e}}$ MacLean Center for Clinical Medical Ethics, Departments of ${ }^{\mathrm{f}}$ Anthropology, ${ }^{\mathrm{g}}$ Pediatrics, and ${ }^{\mathrm{h}}$ Surgery, \\ University of Chicago, Chicago, III., USA
}

\section{Key Words}

Living donor $\cdot$ Kidney donor $\cdot$ Ethics - Adverse outcome .

Psychosocial · Qualitative study

\section{Abstract}

Background: Psychosocial data about living kidney donors have been collected for almost 5 decades now. To date, however, no study has provided any psychosocial follow-up of donors who developed a serious health problem such as end-stage renal disease (ESRD). Methods: Donors who developed ESRD were invited to participate in a qualitative interview if they met one or both of the inclusion criteria: (1) developed ESRD within 10 years of donating and/or (2) lacked health insurance at the time of donation. We contacted 38 individuals who met these criteria, and 22 participated (58\%). Two were subsequently excluded from analysis. $\boldsymbol{R e}$ sults: Twenty qualitative interviews were analyzed. Five findings are described: (1) donors describe the decision-making process as spontaneous and fast; (2) donors describe lack of appreciation for the need for post-donation self-care; (3) donors do not regret donating despite the adverse outcome; (4) donors advise future donors to have in place emotional and physical support post donation; and (5) donors appreciate the opportunity to tell their story from being a living donor to living with ESRD, which virtually all perceive as 2 separate unrelated events. Conclusions: Most donors are positive about their donation decision and experience and would donate again, despite developing ESRD themselves. They propose some important changes to the decision-making and informed-consent processes. Our data are reassuring regarding lack of donor regret, but highlight the need for living donor transplant programs to ensure that living donors understand their long-term risks and receive appropriate life-long follow-up care to minimize these risks.

(c) 2016 S. Karger AG, Basel

\section{Introduction}

It is estimated that over 150,000 individuals have served as living donors in the United States - estimated because for the first 40 years, no systematic data were collected. Since 1996, the Organ Procurement and Transplantation Network (OPTN) has recognized former living donors by awarding them 4 points if they are listed for

\section{KARGER}

E-Mail karger@karger.com www.karger.com/ajn
(C) 2016 S. Karger AG, Basel

$0250-8095 / 16 / 0436-0389 \$ 39.50 / 0$
Lainie F. Ross, MD, $\mathrm{PhD}$

MacLean Center for Clinical Medical Ethics

University of Chicago, 5841 S Maryland Avenue

MC 6082, Chicago, IL 60637 (USA)

E-Mail Lross@uchicago.edu 
a deceased donor kidney. As of May 31, 2015, over 430 candidates have received 4 points (personal communication E. Beeson, United Network for Organ Sharing, September 11, 2015). However, this is an underestimation, as it does not include those living kidney donors who were listed and transplanted before 1996 nor those living kidney donors who developed end-stage renal disease (ESRD) but choose not to be listed for transplant.

Although the OPTN requires only 2 years of clinical and laboratory follow-up data, data collection compliance is poor [1]. However, recent studies show that when donors are followed over longer observation periods, there is an increased risk of ESRD, reproductive complications, and hypertension [2-4]. There is also a dearth of systematic long-term psychosocial follow-up. In the 1970s, Simmons et al. [5] found that donors often decided to donate 'spontaneously'. This was confirmed by Fellner and Marshall $[6,7]$, who showed that the majority rarely changed their decision, even when given extensive data about risks. Simmons et al. [5] also found that donors seldom experienced regret, at least in the short term. In fact, most studies have determined that fewer than $10 \%$ of donors regretted their decision to donate, and this holds even when there are adverse outcomes like graft failure and recipient death [8-14]. To date, however, no study has provided psychosocial follow-up of donors who develop a serious health problem like ESRD. In this manuscript, we include interviews with 20 living donors who subsequently developed ESRD.

\section{Methods}

Design

This project is part of a larger, ongoing study in which one of us (L.F.R.) is recruiting former living donors who developed ESRD to determine whether there are specific biomarkers or genetic risk factors. The Human Resources Services Administration (HRSA), which oversees the OPTN, helped identify participants by providing the names and birthdates of those who had received 4 points. Nephrologists and other transplant professionals around the country helped locate these candidates as well as candidates not known to HRSA. In June 2014, 165 individuals consented to participate in the database and provided tissue samples. Virtually all agreed to be re-contacted for supplemental projects.

The researchers identified 2 sub-groups of interest for this study: (1) those who developed ESRD within 10 years of donating (subgroup under-10) and (2) those who lacked health insurance at the time of donation (subgroup uninsured). Study participants were restricted to donors who had donated to a first-degree family member, but excluded parents who had donated to a child because of the distinctive emotional dynamics of that relationship $[15,16]$. The University of Chicago's Institutional Review Board approved the main project and exempted the oral histories from further review.

\section{Recruitment}

Twenty-five donors developed ESRD within 10 years of donating and 27 donors lacked health insurance at the time of donation. This double-counts 5 who both developed ESRD within 10 years and lacked health insurance. Excluding non-first degree relatives and parent donors resulted in 21 potential participants in subgroup under-10 and 17 potential participants in subgroup uninsured. All were sent a one-page information sheet about the qualitative study and an oral consent document. The information sheet explained that they would be contacted within 2 weeks to determine whether they were interested in participating, or they could contact us in order to set up an interview time. Potential participants were told that the interview would last approximately $60-90$ min and were offered a $\$ 50$ gift card in appreciation for their participation.

\section{Interview Scripts}

We developed 2 overlapping scripts of semi-structured questions, one for each subgroup. All scripts began by asking about the participants' decision to donate their kidney. Questions focused on donors' health, interactions with the transplant team, the impact of subsequent kidney problems on the donor and their family, and closed with a discussion of recommendations, given their experience of the donation process and their subsequent development of ESRD. The script for subgroup under-10 included additional probes regarding family dynamics surrounding the donor's relatively near-term development of ESRD, while the script for the subgroup uninsured devoted additional probes to the patients' experience with the healthcare system and finances. Interview guides are available from the corresponding author.

\section{Data Collection and Analysis}

All participants were interviewed by telephone either by J.Y. Wang or by M. Poulson, except one who was interviewed in person by M. Poulson. All interviews were conducted entirely in English, except one that had Spanish supplementation (L.F.R.), which was translated before coding. A senior researcher (L.F.R.) oversaw the interviews and when salient questions remained, the participants were re-contacted for further questions. Interviews lasted between 40 and $90 \mathrm{~min}$. After 11 interviews in both subgroups, no new concepts were being expressed. Having reached theoretical saturation, no additional participants were recruited [17]. Researchers transcribed the interviews in Microsoft Word and uploaded transcripts to Atlas.ti (software for qualitative data analysis). All researchers participated in the development of the codebook. Four researchers (C.M.E.H., J.K., M.C.-M., and L.F.R.) coded 6 interviews, making modifications to the coding tree iteratively until there was unanimous agreement about the definitions of each code. Two investigators (C.M.E.H. and J.K.) then double-coded each transcript; disagreements between the 2 were reconciled. In this manuscript, participants are identified by gen$\operatorname{der}(\mathrm{F}=$ female, $\mathrm{M}=$ male), by subgroup $(\mathrm{T}=$ under-10, $\mathrm{I}=$ uninsured), and by a unique number.

All interviews were recorded and transcribed. After reviewing the transcripts, researchers developed 25 coding categories. After further consideration of the categories as they had emerged and based on the similarity between interview scripts, it was determined that no significant differences in the qualitative findings existed between the 2 subgroups, and they were merged for analysis. 


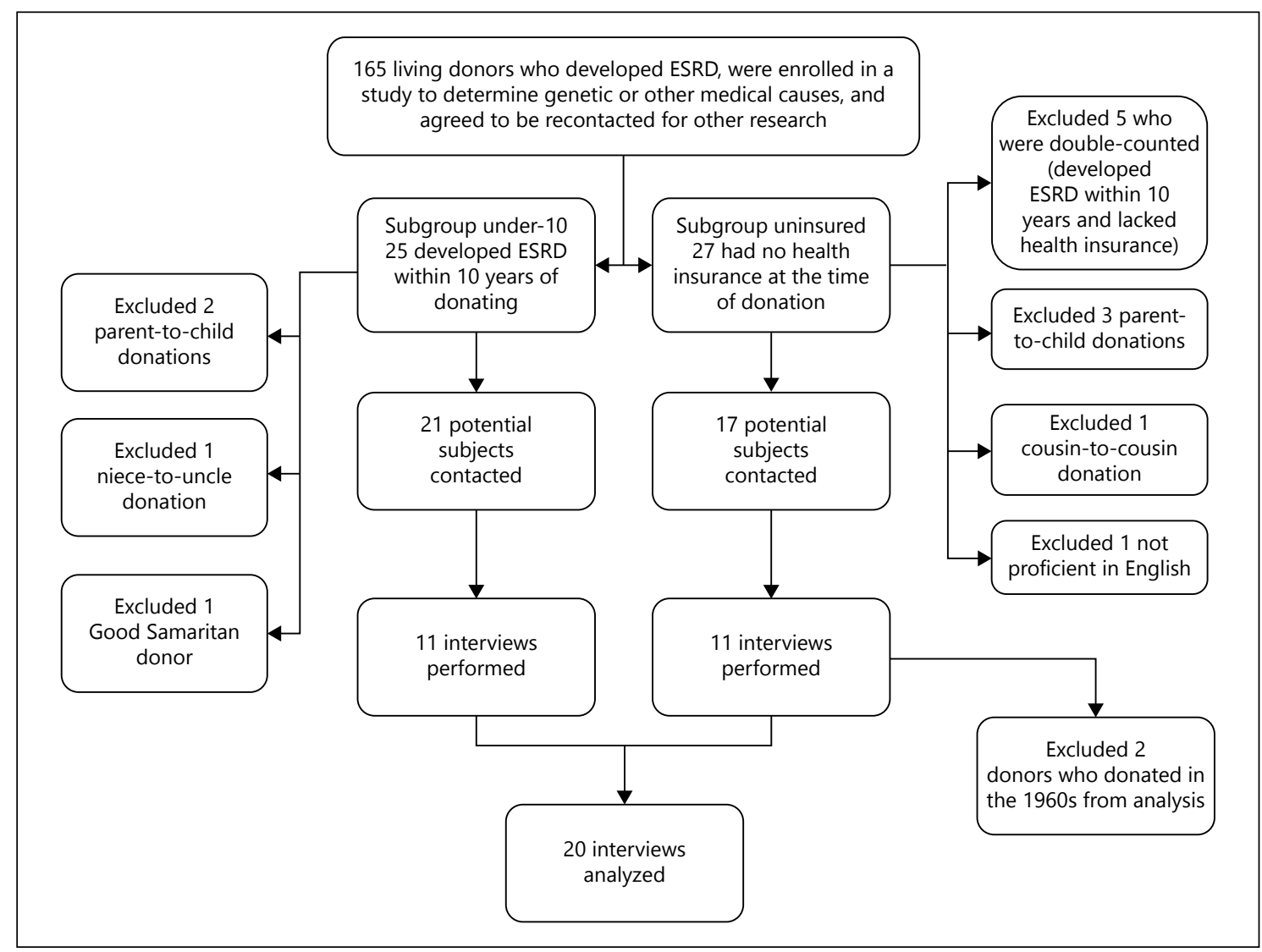

Fig. 1. Flowchart of living donor recruitment and inclusion for analysis.

\section{Results}

\section{Participant Characteristics}

Overall, 47 individuals met the criteria of being uninsured at the time of donation, having developed ESRD within 10 years of donation, or both. Of this group, 27 (57\%) were male. Twenty-one of the individuals (45\%) self-identified as Black, $9(19 \%)$ as Hispanic, $15(32 \%)$ as White, and 2 (4\%) as other. After exclusions, 23 of the 38 potential candidates (61\%) were male. Eighteen (47\%) potential candidates self-identified as Black, $7(18 \%)$ as Hispanic, 12 (32\%) as White, and 1 (3\%) as other.

A total of 22 individuals participated in the interviews, 11 of 21 eligible (52\%) from subgroup under-10 and 11 of 17 eligible (65\%) from among the subgroup uninsured (fig. 1). Two interviews from subgroup uninsured were subsequently excluded from analysis because the donation had occurred in the early 1960s when kidney transplantation was still very experimental and would not have been covered even if the donors had insurance. The demographic data of the 20 participants are not statistically different from the larger set from which they were selected. The majority are male (12 or $60 \%)$ and Black (12 or $60 \%$; table 1 ).

\section{Thematic Findings}

For this study, we describe the findings from 5 coding categories, 4 of which were analyzed in other qualitative research focused on the experiences of living donors and one unique to our project: (1) the decision-making process, (2) instructions for donor self-care after donation, (3) (lack of) regret about having donated, (4) advice for future donors and the donation process, and (5) the impact of the current project on perceptions of their lived experience from donor to recipient.

\section{Decision-Making}

Interviewees did not describe becoming a donor as the result of a decision, but rather, as a spontaneous response to their relative's medical condition. 'I never lost no sleep over it,' one man stated nonchalantly: 'I just said, 'Well, that's my brother; that's all" (FI7). Another woman noted 
Table 1. Demographics $(n=20)$

\begin{tabular}{|c|c|c|c|}
\hline Trait & $\begin{array}{l}\text { Total } \\
(\mathrm{n}=20), \mathrm{n}(\%)\end{array}$ & $\begin{array}{l}\text { Uninsured } \\
(\mathrm{n}=9), \mathrm{n}(\%)^{\mathrm{a}}\end{array}$ & $\begin{array}{l}\text { Under } 10 \\
(\mathrm{n}=11), \mathrm{n}(\%)^{\mathrm{a}}\end{array}$ \\
\hline \multicolumn{4}{|l|}{ Race } \\
\hline Black & $12(60)$ & $4(44)$ & $8(73)$ \\
\hline Hispanic & $4(20)$ & $4(44)$ & $0(0)$ \\
\hline White & $4(20)$ & $1(11)$ & $3(27)$ \\
\hline \multicolumn{4}{|l|}{ Gender } \\
\hline Female & $8(40)$ & $4(44)$ & $4(36)$ \\
\hline Male & $12(60)$ & $5(56)$ & $7(64)$ \\
\hline \multicolumn{4}{|l|}{ Relationship to recipient } \\
\hline Child to parent & $3(15)$ & $0(0)$ & $3(27)$ \\
\hline Sibling & $17(85)$ & $9(100)$ & $8(73)$ \\
\hline \multicolumn{4}{|l|}{ Age at interview } \\
\hline $30 \mathrm{~s}$ & $2(10)$ & $0(0)$ & $2(18)$ \\
\hline $40 \mathrm{~s}$ & $5(25)$ & $1(11)$ & $4(36)$ \\
\hline $50 \mathrm{~s}$ & $5(25)$ & $3(33)$ & $2(18)$ \\
\hline $60 \mathrm{~s}$ & $6(30)$ & $5(56)$ & $1(9)$ \\
\hline $70 \mathrm{~s}$ & $2(10)$ & $0(0)$ & $2(18)$ \\
\hline \multicolumn{4}{|l|}{ Education } \\
\hline Less than high school & $1(5)$ & $1(11)$ & $0(0)$ \\
\hline High school or equivalent & $7(35)$ & $2(22)$ & $5(45)$ \\
\hline Associates or some college & $6(30)$ & $5(56)$ & $1(9)$ \\
\hline Bachelors & $3(15)$ & $0(0)$ & $3(27)$ \\
\hline (Some) graduate & $3(15)$ & $1(11)$ & $2(18)$ \\
\hline \multicolumn{4}{|l|}{ Date of donation } \\
\hline 1970 s & $4(20)$ & $4(44)$ & $0(0)$ \\
\hline 1980s & $5(25)$ & $4(44)$ & $1(9)$ \\
\hline $1990 \mathrm{~s}$ & $4(20)$ & $0(0)$ & $4(36)$ \\
\hline $2000 s$ & $7(35)$ & $1(11)$ & $6(55)$ \\
\hline \multicolumn{4}{|l|}{ Time from donation to ESRD, years } \\
\hline$\leq 10$ & $11(55)$ & $0(0)$ & $11(100)$ \\
\hline$>10$ but $\leq 20$ & $3(15)$ & $3(33)$ & $0(0)$ \\
\hline$>20$ but $\leq 30$ & $5(25)$ & $5(56)$ & $0(0)$ \\
\hline$>30$ but $\leq 40$ & $1(5)$ & $1(11)$ & $0(0)$ \\
\hline \multicolumn{4}{|l|}{ Treatment modality for ESRD at time of interview } \\
\hline First time on waitlist not requiring dialysis & $1(5)$ & $1(11)$ & $0(0)$ \\
\hline First time on waitlist, requiring dialysis & $2(10)$ & $0(0)$ & $2(18)$ \\
\hline On dialysis after 1 or more deceased donor grafts failed & $3(15)$ & $1(11)$ & $2(18)$ \\
\hline Deceased donor graft functioning & $14(70)$ & $7(78)$ & $7(64)$ \\
\hline Living donor graft & $0(0)$ & $0(0)$ & $0(0)$ \\
\hline
\end{tabular}

a Percentages do not always add up to $100 \%$ due to rounding errors.

similarly, 'I didn't think twice about doing it, 'Cause I knew he needed it" (MI6). Likewise, some participants seemed not to have thought retrospectively of their donation as a choice. One participant explained, 'I just kind of felt like it was just - that's just the way it's supposed to be. I never really thought much about it to make a decision' (MT10).

Many participants related this 'non-decision' to the perceived rapidity of the donation process. 'I'm not saying that I would have said 'No,' but I just don't feel like I had a chance to really, really process everything. [...] It went very quickly' (FT8). One participant even went so far as to say, 'Everything happened so quickly that there was not time to think' (FI8).

\section{Regret}

Throughout the interviews, participants were prompted with questions regarding their feelings toward donation. Did they hesitate during the decision-making? Did the varying success of their donated kidney in the recipient 
effect their interpretation of its success? Did they regret donating now that they had themselves gone into ESRD?

The interviewees were resoundingly positive about their original decision to donate: 'The decision I (made), to me, was the right decision,' stated one man (MI4). 'I never regret it,' said a middle-aged woman (FT2). The same interviewee later began to cry while discussing how she found out that her kidney was failing: 'I was upset. Yeah, I was upset, but I have no regrets.'

When asked explicitly, all but one participant stated that they - despite the consequences - would go back in time and donate all over again. For instance, one man said, 'If I had to do it over again, I would do the same thing' (MI3). Another woman responded similarly: 'If I knew my kidney wasn't going to work? I would probably still do it' (FT2). One participant described the difficult conversation he had with his recipient-sister when his one remaining kidney began to fail: 'She was hurt because she felt like it was her fault, because I donated her a kidney and she felt like it was her fault, but I reassured her that it wasn't. I told her that if I had to do it all over again, I mean, it's a no-brainer; I would do it again' (MT6).

Only one interviewee forthrightly stated that she would 'probably not' (FI2) have donated knowing that she would subsequently go into ESRD. She explained that she had a complicated postoperative course and a strained relationship with her recipient-sister. Throughout her interview, however, she oscillated between satisfaction and regret, pensively considering the positive and negative results of her donation. At one point she conceded, 'I probably would have done it again, who knows?' Later in the same interview, she ruminated: 'Had I known that I would be going through this, I don't know. [...] I might've thought a little bit longer.' (It is noteworthy that she characterizes these feelings as 'the hardest thing to say' and 'a bad thing to say.') Earlier, however, despite her wavering, she concluded that she is 'glad I was able to give her the time that I did.'

Several transplants were relatively unsuccessful clinically (lasting less than a few months), but even this did not sway donors in their steadfast lack of regret. 'It wasn't in the cards for my kidney to work for him', one woman said of her recipient, 'but we gave it a shot, because it could have gone either way. It went the wrong way for us, but if need be, I would do it again' (FI6).

\section{Self-Care}

Participants were asked to recall what their healthcare team told them about self-care after donation. Most responded that they had been simply told to live a 'normal life.' For instance, the interviewer asked one woman, 'What did your mom think (about your donating)? Was she concerned like your dad?' The woman responded, 'They were very concerned, only because they wanted me to have a full life after I donated. But really the team we were speaking with, they explained everything to us and they said pretty much that I would be able to have a normal life after donation' (FI6). Unlike her parents, she stated, her healthcare team did not focus extensively on the risks of donation. One man noted that he was so trusting of what he recalls his team telling him, that he disregarded what he now knew to be risk factors for developing ESRD:

They told me that I could live a normal life with one kidney. I used to do construction. I never had high blood pressure or diabetes or anything, and I was putting on a lot of weight. I was living a normal life and just working back and forth, and then [...] I started feeling some symptoms, and I didn't know and then I went to the doctor [...] they said it was my kidney (MT5).

The most important fact that individuals remembered from the risk discussion with the transplant team was that one kidney is sufficient. 'They told me that you can live with one kidney,' one woman explained. 'Well, evidently you can live off of it, but you have to keep yourself healthy, and nobody explained that to me. They told me, 'Go ahead and live your life like you always did" (FI2).

A few of the donors expressed a certain degree of selfblame for their subsequent ESRD. Participants explained that they did not understand the need to take better care of themselves, as evidenced in this quote: 'Somebody should've told me, 'You've got this one kidney. You have to be real careful about your weight. You have to be real careful about eating and doing different things.' I mean, if they had, I don't think that this probably would've happened to me. I just assumed you could go ahead and live your life the way you've always been living with two' (FI2).

Another woman lamented, 'I think I was careless. I remember in the summer having a sore throat and not going to the doctor because I just - you're a mom; you don't think about that stuff (FI6).

While some blamed their subsequent kidney failure on 'tough luck' (MT12) or 'God('s) reasons' (MT5), none explicitly stated that their donation was in part responsible for the development - or even the timing of their own kidney failure. One respondent, however, offered that his spouse was not certain: 'She, I know, in the back of her mind, still feels that maybe some people didn't basically do as thorough a job on the medical side to fully look at my circumstances and maybe would 
have detected something which would have said, 'Hey, maybe you shouldn't do this because you've got some some issues looming" (MT12).

\section{Advice}

Participants were asked how they would change the donation process. Most stated they would not change anything. 'I think they did a good job, and I think that hopefully they can continue,' one woman said (FI1). Another respondent responded similarly, 'No. [...] They did everything right' (MT4).

Similarly, many individuals gave blanket endorsements for donating a kidney: 'I would definitely encourage anybody to be a donor,' declared one woman (MI6). 'Another woman explained: I would tell (potential donors) to do it. Don't be scared; just take the test and just, you know, you're doing a good thing. Don't have regrets. Think about it first and, you know, be sure that you don't have any regrets. You're helping someone else' (FT2).

However, some provided advice about self-care post donation. Many stated that they did not seek preventive health care for years or decades after being discharged from follow-up by the transplant team, and that transplant teams need to emphasize the long-term risks with donation: 'I wish they don't say to everybody, 'Oh yeah, you going to be okay, no problem,' because (it) can be a big problem' (MI4). Another man noted the importance of self-observation: 'When you think you sick, before you get sick, you should go (to the doctor). And that's what I do now. I go to the urologist; I go to the cardiologist; I go to the optometrist [...] I go to A through $\mathrm{Z}$ now' (MI8).

Several participants advised that prospective donors have a strong community to rely on during and after recovery. One man expressed serious disappointment that his family checked in on the recipient postoperatively but not on him. He advised: 'Make sure that (the donors) have a good support group around them [...] at least a couple people that would drop in and see if they're okay' (MT10). Some also recommended that healthcare teams set the donor up with an 'advocate [...] like a counselor' (FT9).

Despite their own experience of serious harm (kidney failure), very few comments were directed at the perceived dangers of donation. 'Make sure it's something that you really, really are willing to risk your health and life in doing,' one woman exhorted potential donors (FT9). However, some donors stated that the physicians should have been more explicit about the risks. For example, one donor stated:
All the doctors, everybody, said, 'Oh, you're going to live the same; it's not going to be any problem for you and your kidneys.' [...] But if somebody at the time (told) me the risks - 'Maybe you're going to end in renal failure' - [...] It's not like maybe I don't change the decision to donate, but I wish to at least know (MI4).

\section{Study Impact}

Many of the interviewees valued being asked to tell the story of their trajectory from kidney donor to transplant candidate, although most had not considered any connection between donation and developing ESRD. In several of our interviews, participants mentioned that our study had caused them to reflect on the relationship between these events. One man stated that he would not have considered a connection between his donation and later development of ESRD from lupus 'had you not called me and prompted me to think about (it)' (MT12). That said, he - and almost everyone else - remained very positive about donation.

One participant differed in that he made explicit that he had intentionally abstained from thinking about the relationship between his donation and his health. He described initial anger and resentment after donation that he had subsequently worked hard to stifle: 'I've been suppressing these thoughts, 'cause I really never told my story. [...] I'm going to put them thoughts - I'm going to close that door and open that file cabinet no more. [...]' (MI10).

\section{Discussion}

This is the first study to focus on the attitudes and psychological outcomes of living donors who subsequently developed ESRD. A key and somewhat surprising finding of our study is that despite their universal adverse outcome, our donors' recollection of their donation experience is mainly positive and mirrors the psychological findings in studies involving living donors who did not have serious adverse health outcomes [5, 18-20]. Our donors made spontaneous decisions and for the most part (95\%) have no regret despite the adverse outcome. Studies in which donors did not develop ESRD have found parallel results, with no or few participants $(<10 \%)$ expressing regret for having donated [8-14].

Most participants recall the donation process as rapid and do not attend to any warnings for modifying behaviors. Our donors interpreted 'you can live with one kidney' as meaning they did not need to take precautions regarding their health. Whether this accurately represents the discussion they had with their transplant team 
is unknown, although one must remember that until very recently, most data were single-center studies that were underpowered to show long-term risks [21-25]. However, even among these small studies, a few authors suggested that there may be some risk to donation and encouraged the establishment of donor registries [26-28]. That said, it has only been in the past 5 years that large studies over longer observation periods have had the power to show an increased risk of ESRD [3,4] and pregnancy complications in former living kidney donors [2, $29,30]$. These studies and our data confirm: (1) that the current OPTN requirement of 2 years living kidney donor follow-up is inadequate as many health complications may not appear for years or decades and (2) that long-term living donor registries are needed [31-33]. The new risk data also highlight the need for best practices for long-term follow-up care and robust informed consent discussions that focus on both short- and long-term risks. Furthermore, studies are needed to determine: (1) how to ensure that donors understand their need for life-long care and (2) whether this care should occur at a transplant center, a nephrology clinic, or with a primary care doctor.

Unique to our study is the advice that our participants offered to the transplant community. Like other donors, they support living donor kidney transplants because of the significant benefits they offer both recipients and donors [5-7, 34]. However, some of our respondents negatively described the lack of support they received postoperatively because they were presumed healthy, and advised counseling donors to ensure good postoperative support. They also recommended that living donors be taught to perceive themselves not as 'healthy' but rather 'healthy but at risk' and to seek medical attention for what may seem to be trivial concerns to ensure kidney well-being.

Some respondents stated that the enrollment in the larger project and the subsequent request to interview them made them more aware of the possible link between their donation and their long-term kidney problems. This may be due to a more explicit consent process during the main project that describes the goal of the study to determine risk factors for ESRD after kidney donation. We were careful to explain that it cannot be known in any particular case whether they would have developed ESRD if they had not donated (unless the cause of ESRD was unilateral traumatic injury to the remaining kidney). We further explained that one of the greatest risk factors for developing ESRD is having a family history of $\operatorname{ESRD}[35,36]$.

There are many reasons why donors may not have previously connected donation and ESRD. First, it is only recently that the kidney transplant community has em- pirical data to show the increased risk of kidney disease in living donors $[3,4]$. Second, it is possible that the transplant community did not explore the possible link when former donors present with ESRD but rather treats these as separate events.

There are several limitations to our study. First, our participants were quite heterogeneous in the time elapsed since living kidney donation, which may influence their recall of events around donation. They are also at different stages of adaptation to living with ESRD - one was predialysis, others are on dialysis or have received a transplant. Current state of health and adaptation to ESRD may also impact the attitudes expressed and the narratives generated about their trajectory from donor to individual in ESRD. Second, donors' answers regarding regret may reflect cognitive dissonance [37] or a social desirability bias [38]. Third, we limited our data analysis to first-degree relatives other than parents donating to their children. Further research is needed to know whether other donorrecipient relationships elicit the same responses.

Despite these limitations, our study provides unique insight into a population that has not been systematically identified nor well studied. Our data are reassuring in that our donors do not regret their donation, despite the fact that they themselves develop ESRD. This does not mean, however, that we can be complacent about donors' understanding of the decision-making process or of the risks and consequences of living kidney donation. Ensuring that living donors understand their long-term risks and receive appropriate life-long follow-up care to minimize these risks should be a priority task in living donor kidney transplantation.

\section{Acknowledgments}

We would like to thank all of the donors who participated in this study. We would like to thank Sandi Cohen who helped work on the interview guides.

\section{Disclosure Statement}

The authors declare no conflicts of interest. C.M.E. Halverson was funded by the MacLean Center for Clinical Medical Ethics and the Department of Pediatrics at the University of Chicago. J.Y. Wang was funded by the University of Chicago Summer Research Program and NIH grant number 2T35D062719-26 (PI: Eugene Chang, MD). M. Poulson and J. Karlin were funded by the MacLean Center for Clinical Medical Ethics. L.F. Ross was funded by a Robert Wood Johnson Investigator Award in Health Policy. The authors have no other funding sources to be declared. The funders had no role in study design or data interpretation. 


\section{References}

1 Schold JD, Buccini LD, Rodrigue JR, Mandelbrot D, Goldfarb DA, Flechner SM, Kayler LK, Poggio ED: Critical factors associated with missing follow-up data for living kidney donors in the United States. Am J Transplant 2015;15:2394-2403.

2 Ibrahim HN, Akkina SK, Leister E, Gillingham K, Cordner G, Guo H, Bailey R, Rogers T, Matas AJ: Pregnancy outcomes after kidney donation. Am J Transplant 2009;9:825-834.

3 Mjøen G, Hallan S, Hartmann A, Foss A, Midtvedt K, Øyen O, Reisæter A, Pfeffer P, Jenssen T, Leivestad T, Line PD, Øvrehus M, Dale DO, Pihlstrøm H, Holme I, Dekker FW, Holdaas H: Long-term risks for kidney donors. Kidney Int 2014;86:162-167.

4 Muzaale AD, Massie AB, Wang MC, Montgomery RA, McBride MA, Wainright JL, Segev DL: Risk of end-stage renal disease following live kidney donation. JAMA 2014;311: 579-586.

5 Simmons RG, Klein SD, Simmons RL: Gift of Life: The Social and Psychological Impact of Organ Transplantation. New York, John Wiley \& Sons, 1977.

6 Fellner CH, Marshall JR: Twelve kidney donors. JAMA 1968;206:2703-2707.

7 Fellner CH, Marshall JR: Kidney donors - the myth of informed consent. Am J Psychiatry 1970;126:1245-1251.

8 Rodrigue JR, Vishnevsky T, Fleishman A, Brann T, Evenson AR, Pavlakis M, Mandelbrot DA: Patient-reported outcomes following living kidney donation: a single center experience. J Clin Psychol Med Settings 2015; 22:160-168

9 Frade IC, Fonseca I, Dias L, Henriques AC, Martins LS, Santos J, Sarmento M, Lopes A: Impact assessment in living kidney donation: psychosocial aspects in the donor. Transplant Proc 2008;40:677-681.

10 Franklin PM, Crombie AK: Live related renal transplantation: psychological, social, and cultural issues. Transplantation 2003;76: 1247-1252.

11 Binet I, Bock AH, Vogelbach P, Gasser T, Kiss A, Brunner F, Thiel G: Outcome in emotionally related living kidney donor transplantation. Nephrol Dial Transplant 1997;12:19401948.

12 Isotani S, Fujisawa M, Ichikawa Y, Ishimura T, Matsumoto O, Hamami G, Arakawa S, Iijima K, Yoshikawa N, Nagano S, Kamidono S: Quality of life of living kidney donors: the short-form 36-item health questionnaire survey. Urology 2002;60:588-592.
13 Wiedebusch S, Reiermann S, Steinke C, Muthny FA, Pavenstaedt HJ, Schoene-Seifert B, Senninger N, Suwelack B, Buyx AM: Quality of life, coping, and mental health status after living kidney donation. Transplant Proc 2009;41:1483-1488.

14 Clemens K, Boudville N, Dew MA, Geddes C, Gill JS, Jassal V, Klarenbach S, Knoll G, Muirhead N, Prasad GV, Storsley L, Treleaven D, Garg AX; Donor Nephrectomy Outcomes Research (DONOR) Network: The long-term quality of life of living kidney donors: a multicenter cohort study. Am J Transplant 2011; 11:463-469.

15 Zeiler K, Guntram L, Lennerling A: Moral tales of parental living kidney donation: a parenthood moral imperative and its relevance for decision making. Med Health Care Philos 2010;13:225-236

16 Burnell P, Hulton SA, Draper H: Coercion and choice in parent - child live kidney donation. J Med Ethics 2015;41:304-309.

17 Glaser BG, Strauss AL: The constant comparative method of qualitative analysis; in The Discovery of Grounded Theory: Strategies for Qualitative Research. Chicago, Aldine Publishing Co., 1967.

18 Fehrman-Ekholm I, Brink B, Ericsson C, Elinder CG, Dunér F, Lundgren G: Kidney donors don't regret: follow-up of 370 donors in Stockholm since 1964. Transplantation 2000;69:2067-2071.

19 Messersmith EE, Gross CR, Beil CA, Gillespie BW, Jacobs C, Taler SJ, Merion RM, Jowsey SG, Leichtman AB, Hong BA; RELIVE Study Group: Satisfaction with life among living kidney donors: a RELIVE study of long-term donor outcomes. Transplantation 2014;98: 1294-1300.

20 Jacobs CL, Gross CR, Messersmith EE, Hong BA, Gillespie BW, Hill-Callahan P, Taler SJ, Jowsey SG, Beebe TJ, Matas AJ, Odim J, Ibrahim HN; RELIVE Study Group: Emotional and financial experiences of kidney donors over the past 50 years: the RELIVE study. Clin J Am Soc Nephrol 2015;10:2221-2231.

21 Fehrman-Ekholm I, Nordén G, Lennerling A, Rizell M, Mjörnstedt L, Wramner L, Olausson M: Incidence of end-stage renal disease among live kidney donors. Transplantation 2006;82:1646-1648.

22 Najarian JS, Chavers BM, McHugh LE, Matas AJ: 20 years or more of follow-up of living kidney donors. Lancet 1992;340:807-810.

23 Liounis B, Roy LP, Thompson JF, May J, Sheil AG: The living, related kidney donor: a follow-up study. Med J Aust 1988;148:436-437, 440-444.
24 Haberal M, Karakayali H, Moray G, Demirag A, Yildirim S, Bilgin N: Long-term follow-up of 102 living kidney donors. Clin Nephrol 1998;50:232-235.

25 Melchor JL, Gracida C, Lopez A: Living donors in kidney transplantation: five-year follow-up. Transplant Proc 1998;30:2869-2870.

26 Azar SA, Nakhjavani MR, Tarzamni MK, Faragi A, Bahloli A, Badroghli N: Is living kidney donation really safe? Transplant Proc 2007; 39:822-823.

27 Ramcharan T, Matas AJ: Long-term (20-37 years) follow-up of living kidney donors. Am J Transplant 2002;2:959-964.

28 Saran R, Marshall SM, Madsen R, Keavey P, Tapson JS: Long-term follow-up of kidney donors: a longitudinal study. Nephrol Dial Transplant 1997;12:1615-1621.

29 Lam NN, Lentine KL, Levey AS, Kasiske BL, Garg AX: Long-term medical risks to the living kidney donor. Nat Rev Nephrol 2015;11: 411-419.

30 Garg AX, Nevis IF, McArthur E, Sontrop JM, Koval JJ, Lam NN, Hildebrand AM, Reese PP, Storsley L, Gill JS, Segev DL, Habbous S, Bugeja A, Knoll GA, Dipchand C, MonroyCuadros M, Lentine KL; DONOR Network: Gestational hypertension and preeclampsia in living kidney donors. N Engl J Med 2015; 372:124-133

31 Tong A, Chapman JR, Wong G, de Bruijn J, Craig JC: Screening and follow-up of living kidney donors: a systematic review of clinical practice guidelines. Transplantation 2011;92: 962-972.

32 Davis CL, Cooper M: The state of U.S. living kidney donors. Clin J Am Soc Nephrol 2010; 5:1873-1880.

33 Davis CL: Living kidney donor follow-up: state-of-the-art and future directions. Adv Chronic Kidney Dis 2012;19:207-211.

34 Switzer GE, Dew MA, Twillman RK: Psychosocial issues in living organ donation; in Trzepacz P, Dimartini A (eds): The Transplant Patient: Biological, Psychiatric and Ethical Issues in Organ Transplantation. New York, Cambridge University Press, 2000, pp 42-66.

35 Hsu CY, Iribarren C, McCulloch CE, Darbinian J, Go AS: Risk factors for end-stage renal disease: 25-year follow-up. Arch Intern Med 2009; 169:342-350.

36 Satko SG, Freedman BI, Moossavi S: Genetic factors in end-stage renal disease. Kidney Int Suppl 2005;94:S46-S49.

37 Festinger L: A Theory of Cognitive Dissonance. Palo Alto, Stanford University Press, 1957.

38 Tourangeau R, Yan T: Sensitive questions in surveys. Psychol Bull 2007;133:859-883. 